Artigo original

Hegemonia - Revista Eletrônica de Relações Internacionais do Centro Universitário Unieuro

ISSN: $1809-1261$

UNIEURO, Brasília, número 15, 2015, pp. 4-16.

Recebido em: 29/3/2015

Avaliado em:14/5/2015

Aprovado em: 18/6/2015

\title{
Aquiescência na Líbia: O Nascimento de uma Democracia?
}

Erinaldo Carmo ${ }^{1}$, Younus Haddod ${ }^{2}$, e Fernanda Ferreira ${ }^{3}$

Resumo: O presente artigo resulta de um estudo sobre as mudanças ocorridas, e ainda em curso, na Líbia após a queda do regime autoritário e na implantação de mecanismos democráticos de governo. Depois de uma série de ações desastrosas do governo de Khadafi, nos âmbitos nacional e internacional, os protestos levaram a sociedade a uma intervenção bélica direta sobre o governo e sobre o Estado. Esse trabalho ainda apresenta alguns aspectos da problemática decorrente da contradição ideológica entre Secularismo e Islamismo Político, no que diz respeito à participação no novo Estado. Essa temática adquiriu uma importância acentuada nos atuais debates políticos no Mundo Árabe, com a busca de uma solução democrática entre essas duas correntes antagônicas, cujo confronto precisa sair da luta armada para o diálogo conciliatório.

Doutor em Ciência Política. Professor da Universidade Federal de Pernambuco.

Doutorando do Centro de Estudos Sociais da Universidade de Coimbra. 
Artigo original

Hegemonia - Revista Eletrônica de Relações Internacionais do Centro Universitário Unieuro

ISSN: 1809-1261

UNIEURO, Brasília, número 15, 2015, pp. 4-16.

Palavras-chave: Líbia. Secularismo. Islamismo político. Mundo Árabe, Democracia.

Abstract: This article results from a study on the changes taking place, and still ongoing in Libya after the fall of the authoritarian regime and the implementation of democratic governance mechanisms. After a series of disastrous actions of Gaddafi's government at the national and international levels, the protests led the company to a direct intervention war on the government and the State. This work also presents some aspects of the issues arising from the ideological conflict between secularism and political Islam, with regard to participation in the new state. This theme has acquired a marked importance in current political debates in the Arab world, with the search for a democratic solution between these two antagonistic currents, whose confrontation have to leave the armed struggle for conciliatory dialogue.

Keywords: Libya. Secularism. Political Islam. Arab World, Democracy.

Introdução

Algumas questões relevantes precederam a mobilização popular, a atuação de grupos armados e a intervenção da comunidade internacional, ações conjuntas que derrubaram o regime ditatorial do coronel Muammar Khadafi na Líbia em 2011. Trataremos aqui das sanções econômicas, condicionalidades políticas, isolamento e pressões internas e externas que por décadas foram impostas ao Estado líbio. Nesse contexto, a transição para um possível estágio da democracia, ainda que inicial, resulta de razões ligadas a três fatores fundamentais: o desejo da população pela liberdade e pelos valores democráticos; a insatisfação atribuída à crise econômica e incapacidade do governo em atender às demandas da sociedade; e a natureza atroz das ações terroristas do governo no meio externo. A síntese da interação desses três fatores interdependentes foi marcante na condução à erosão da legitimidade do antigo sistema, sua instabilidade e, finalmente, sua desintegração.

Após a Guerra Fria, o foco da política exterior dos Estados Unidos da América se deslocou do confronto ideológico com a exUnião Soviética para uma série de questões ligadas à promoção da democracia, à solução de conflitos decorrentes da transição 
Artigo original

Hegemonia - Revista Eletrônica de Relações Internacionais do Centro Universitário Unieuro

ISSN: 1809-1261

UNIEURO, Brasília, número 15, 2015, pp. 4-16.

democrática e ao enfrentamento do terrorismo e dos sistemas antidemocráticos. Essa mudança de rumo na política externa dos EUA levou essa potência a novas incursões no mundo periférico, fora do eixo norte-ocidental, inclusive na atuação direta na queda de antigos regimes, inclusive o existente no Estado líbio.

Entretanto, com a queda do regime ditatorial, nasceram outros conflitos no novo Estado líbio, que representam os aspectos mais dificultosos à estabilidade administrativa do país e à formação de sua democracia. Duas correntes divergem sobre o tipo de Estado a ser estabelecido: a Federalista e a Unitarista. Porém, o maior conflito gira em torno de dois vetores opostos que têm dominado o debate político na Líbia: o Secularismo e o Islamismo Político. O primeiro fundamentado na democracia liberal e o segundo ligado à concepção islâmica.

As duas correntes opostas

Depois da Segunda Guerra Mundial, os países árabes, sucessivamente, conseguiram adquirir a independência e os secularistas, notadamente de inclinação esquerdista e representada em geral por militares, delimitaram o espaço das liberdades e dos direitos através do monopólio dos recursos do conhecimento, da legislação e do poder político e econômico. Com isso, os governantes árabes secularistas desvincularam-se da realidade dos seus povos. Isso preparou o solo para uma reação violenta por parte de grupos religiosos. Logo depois da queda dos regimes seculares pelos levantes da Primavera Árabe, a situação pareceu favorável para que o modelo do Islamismo Político fosse aplicado. E assim começou outra rodada de conflitos entre as duas correntes. No passado, os métodos seculares árabes foram acompanhados por projetos ditatoriais. No presente, a democracia mudou, inicialmente, a situação a favor do Islamismo Político, que semelhantemente repetiu a mesma experiência ditatorial com a tentativa de islamização do Estado, o que fortaleceu os seculares na luta pela retomada do poder.

Nos regimes derrubados pela Primavera Árabe, geralmente marcados por princípios déspotas personalizados, os ditadores 
Artigo original

Hegemonia - Revista Eletrônica de Relações Internacionais do Centro Universitário Unieuro

ISSN: 1809-1261

UNIEURO, Brasília, número 15, 2015, pp. 4-16.

concentravam os recursos do poder, do conhecimento e da lei em suas mãos. Com isso, tanto as facções da corrente secular, quanto as do Islamismo Político, como também as categorias populares, foram fortemente impedidas da participação ativa. Essa exclusão, acompanhada de uma forte repressão, foi uma prática responsável pela dissolução desses regimes. Observa-se que as práticas de exclusão e do confronto recíproco continuam ameaçando a legitimidade do regime democrático recém-nascido e a contradição entre as duas correntes ainda parece inconciliável.

De uma forma geral, o Islamismo Político, como todos os grupos pertencentes à corrente islâmica, defende os princípios religiosos como forma de união de todos os grupos islâmicos, a Umma (comunidade de todos os muçulmanos do mundo, unida pela crença no profeta Maomé e guiada pelas orientações do Alcorão). Isso corresponde ao que Ibraheem (2011) apresenta como o conteúdo da política constitucional de Sharia, um conjunto de relações que une governantes e governados dentro de uma mesma rede de direitos e obrigações recíprocas. A governança em nome de Sharia considera que a Constituição e as leis, os modos de vida e do comportamento social devem seguir a Lei Divina derivada da interpretação do Alcorão (Sharia), os discursos e atos explicadores das normas do Profeta Maomé (Sunnah) e as tradições dos Califas, sucessores do Profeta.

Esses princípios sagrados constituem uma fonte única de reconhecimento e de apoio aos grupos políticos islâmicos, que podem ser divididos em duas correntes: a dos moderados e a dos radicais. A primeira adota o método mais democrático, enquanto a segunda o rejeita completamente. O grupo da Irmandade Muçulmana, por exemplo, representa a primeira categoria, enquanto os grupos Ansar al-Sharia, Jihad e Al-Qaeda representam a segunda. Zahir (1994) lembra que quando o Estado do Paquistão tornou-se independente, em 1947, Muhammad Assad foi encarregado como Presidente do Comitê de Promulgação da Constituição do Estado Islâmico Paquistanês. Ele passou três anos procurando no Alcorão e nas normas do Profeta Maomé sobre projeto de Estado ou constituição, mas seus esforços foram em vão. 
Artigo original

Hegemonia - Revista Eletrônica de Relações Internacionais do Centro Universitário Unieuro

ISSN: 1809-1261

UNIEURO, Brasília, número 15, 2015, pp. 4-16.

A corrente islâmica entende que Deus formulou todos os detalhes da vida e por isso é necessário que o texto sagrado seja evocado na política, no Estado, na governança e na sociedade. Os secularistas, ao contrário, apresentam uma visão do Estado e da sociedade que não confunde o texto sagrado e o texto humano. Essa visão secular pressupõe que a mente humana é capaz de mobilizar os mecanismos do Estado e da sociedade. Os grupos islâmicos, notadamente os mais radicais, não aceitam a democracia como sistema de governo, porque os princípios democráticos contradizem o Islã, por conceder competências de legislação ao povo e aos seus representantes, em vez de Deus. Na observação de Alfadl (2003), os partidos moderados do Islamismo Político, representantes da corrente islâmica nos Congressos Nacionais, já possuíam poderes com a ocupação de cargos importantes, mas só após a derrubada do poder ditatorial, passaram a ocupar o posto de comando do governo.

Por isso, Al-Alimi (2014) observa que a corrente islâmica tem receios da exclusão herdada de sua experiência histórica de repressão pelo Estado. Pela primeira vez esse grupo experimentou o exercício do poder, como resultado da Primavera Árabe, alcançando uma vasta margem de liberdade de ação. A frustração dessa corrente ocorreu em 2013, no Egito, quando o presidente eleito, Mohamed Mursi, foi deposto um ano após assumir o cargo. O que ocorreu com o Partido da Irmandade Muçulmana egípcio afetou a corrente islâmica em outros países da região. E o receio dessa corrente pelo retorno da exclusão tem provocado uma intensificação das ações violentas.

O estabelecimento de um processo de democratização na Líbia pressupõe a devida adequação em três instâncias constitutivas desse país: o governo, as instituições e o povo. A primeira instância, em nível de governo central, obteve uma mudança drástica com a derrubada do poder ditatorial de Khadafi e o estabelecimento de um novo governo, em contato mais próximo com a população do país. No que diz respeito às instituições, estas não obtiveram mudanças tão instantâneas quanto o governo, mas têm procurado se ajustar aos princípios democráticos com o estabelecimento de novas regras e práticas de trabalho que consideram as necessidades e demandas populares e buscam contemplar em suas ações às novas demandas 
Artigo original

Hegemonia - Revista Eletrônica de Relações Internacionais do Centro Universitário Unieuro

ISSN: 1809-1261

UNIEURO, Brasília, número 15, 2015, pp. 4-16.

sociais. Tanto o novo governo quanto as instituições líbias apresentam agora uma alteração de rota rumo à formação de um novo Estado. Mas e o povo?

É possível descrever o povo líbio como um conjunto de tribos diversas com baixa experiência democrática. Essa geração ativamente participante dos movimentos de derrubada do regime não havia conhecido a democracia em seu país. O longo período de governo autoritário de Khadafi fez com que a população não tivesse contatos ou referências democráticas em seu próprio meio. Porém, as relações desses mais jovens com grupos externos sempre foi algo presente. Isso porque, como bem sabemos, as fronteiras africanas são artificiais, estabelecidas pelos colonizadores europeus no Século XIX, e com isso tribos foram separadas em países diferentes e o tempo não extinguiu os laços familiares e tribais, fazendo com que as relações afetivas cruzassem as limitações geográficas e os impedimentos estatais de domínio e controle do espaço territorial. Cidadãos líbios mantinham contatos permanentes com parentes e amigos na Argélia, Tunísia e Egito. De outro lado, apesar de manterse fechado durante o regime autoritário, o Estado líbio permitiu a muitos jovens frequentar escolas e universidades europeias.

A proximidade entre os países da África Meridional e a Europa favoreceu o intercâmbio de estudantes que conheceram a democracia em diferentes sociedades europeias, visões de mundo que voltaram ao país de origem através dos mais jovens. A proximidade dos continentes também favoreceu as migrações, existindo diversas famílias líbias com parentes vivendo em países europeus, com os quais cultivavam contatos. O sonho das liberdades trazidas pela democracia incitou-os à ostentação das indignações e descontentamentos e aos protestos em massa, sobretudo após o sucesso do movimento no principal país vizinho, o Egito, onde o governo de Hosni Mubarak desmoronou após 30 anos no poder.

O terrorismo de Estado

A primeira relação conflitante entre a Líbia e os EUA nos remetem à Guerra de Trípoli (1801-1805), quando o presidente 
Artigo original

Hegemonia - Revista Eletrônica de Relações Internacionais do Centro Universitário Unieuro

ISSN: 1809-1261

UNIEURO, Brasília, número 15, 2015, pp. 4-16.

americano Thomas Jefferson impôs um bloqueio naval e o navio de guerra Philadelphia, encarregado da missão, foi capturado pela força marítima de Trípoli, então uma Província otomana. Desde então houve uma trégua até o final da Segunda Guerra Mundial, com a derrota do Eixo, quando a Inglaterra ocupou o Norte da Líbia, então dominado pela Itália, e concedeu a base aérea militar Al-Mellaha, em Trípoli, aos EUA em 1943, nomeada posteriormente Wheelus. Depois da Independência, em 1947, os governos da Líbia e dos EUA assinaram um acordo de permanência das tropas estadunidenses na base até dezembro de 1971, mas em setembro de 1969 o Rei Idris I foi deposto pelo golpe de Khadafi e a desocupação da base foi antecipada para junho de 1970.

O governo de Khadafi agia violentamente no âmbito interno através do despotismo, e no âmbito externo através do terrorismo. A violência interna atingiu todas as instituições nacionais, inclusive a educação, onde os programas foram alvos de modificações arbitrárias, enquanto alunos e professores foram sumariamente executados ou afastados de suas atividades. Os direitos de propriedade foram violados pela desapropriação e confisco de bens. As ações violentas aumentaram na década de 1980, como afirma Arrgaei (2009), quando a oposição líbia refugiada nos países ocidentais foi perseguida. Os esquadrões da morte, instituídos secretamente pelo governo, executaram ativistas pertencentes à oposição em Bonn, Milão, Atenas, Roma e Londres.

Em agosto de 1981, jatos líbios foram derrubados pela Força Aérea dos EUA no Golfo de Sirte. Isto porque o ditador Khadafi declarou que essa região fazia parte do território líbio, violando os tratados internacionais, o que levou os EUA a fazerem inicialmente um protesto oficial, que foi ignorado pelo governo líbio. Em 1982, o governo de Ronald Reagan impôs um embargo comercial sobre a Líbia, inclusive afetando a exportação de petróleo. Como consequência dessa decisão, o rendimento do Estado líbio caiu drasticamente. Em 1986, o regime líbio foi acusado de envolvimento em atentados palestinos nos aeroportos de Roma e Viena, e em abril do mesmo ano uma bomba explodiu em um clube de Berlin, fatos que levaram os EUA a atacarem as residências de Khadafi nas cidades de 
Artigo original

Hegemonia - Revista Eletrônica de Relações Internacionais do Centro Universitário Unieuro

ISSN: 1809-1261

UNIEURO, Brasília, número 15, 2015, pp. 4-16.

Trípoli e Benghazi. A década de 1980 encerrou-se com o atentado contra o avião americano da Pan Am na cidade inglesa de Lockerbie, em 21 de dezembro de 1988, e outro contra um avião francês da UTA, em 10 de setembro de 1989. Mais que 400 pessoas morreram em ambos os atentados.

Foram esses atentados os episódios que levaram EUA, Inglaterra e França a recorrerem ao Conselho de Segurança da Organização das Nações Unidas com o pedido de sanções ao governo líbio, quando ONU adotou uma série de sanções, incluindo o congelamento parcial de fundos líbios no exterior e uma precaução no fornecimento de equipamentos industriais petrolíferos. O Conselho ainda impôs a proibição de voos, a suspensão do comércio de armas e a redução no tamanho das missões diplomáticas líbias no exterior. Só em 27 de agosto de 1998 o Conselho de Segurança da ONU suspendeu as sanções ao Estado líbio depois do cumprimento das obrigações determinadas e da entrega às autoridades internacionais dos indivíduos acusados pelo atentado terrorista contra a Pan Am.

O difícil caminho à democracia

Mesmo depois da queda do regime de Khadafi e a instituição de um governo provisório logo após o encerramento dos protestos da Primavera Árabe, a situação política na Líbia permanece delicada, com a classe dirigente enfrentando inúmeros desafios herdados do regime passado, que por 42 anos desmantelou o Estado e deixou tudo a ser reconstruído. Apesar de alguns avanços recentes, existem preocupações emergenciais no que se refere à segurança da população e à manutenção da ordem. O governo nacional não tem conseguido impor a sua autoridade às milícias que se formaram e se legitimaram na revolta contra a ditadura. As forças locais que não se sentem contempladas nas ações do Estado nacional continuam lutando com a mesma intensidade que lutaram na eliminação do poder ditatorial de Khadafi.

$\mathrm{Na}$ cidade de Benghazi, na luta por mais autonomia para a região de Cyrenaica, no litoral leste do país, a milícia liderada por Ibrahim al-Jathran chegou a bloquear terminais de exportação de 
Artigo original

Hegemonia - Revista Eletrônica de Relações Internacionais do Centro Universitário Unieuro

ISSN: 1809-1261

UNIEURO, Brasília, número 15, 2015, pp. 4-16.

petróleo e sitiar a cidade com o fechamento do aeroporto e de alguns prédios públicos. Os frequentes protestos em Benghazi exigem novas eleições parlamentares e também a realização imediata de eleições presidenciais, além da suspensão do Congresso Geral Nacional (CGN), que desde a morte de Khadafi tornou-se a principal autoridade política líbia, formado por deputados eleitos no início de 2012 para um mandato emergencial até a normalização do país, a regularização dos serviços públicos e a realização de novas eleições.

O primeiro governo de transição, liderado por um primeiroministro eleito no CGN, apresentou dificuldades em impor a ordem em regiões controladas por milicianos e em março de 2014 os membros do CGN o depuseram e logo nomearam o seu sucessor, o primeiro-ministro interino, Abdullah al-Thinni, com a responsabilidade de formar um novo governo na tentativa de estabilizar as relações políticas nacionais. Poucos dias depois, esse renunciou afirmando ter sofrido graves ameaças de grupos oposicionistas.

Outro problema enfrentado no país diz respeito à baixa participação política no processo eleitoral para o legislativo e à crise política oriunda da disputa entre nacionalistas liberais e islamitas pelo exercício do poder executivo, fato que permeia de instabilidade o Estado nacional. Há na população uma descrença na política nacional e o consequente afastamento do eleitor que não se vê contemplado nas ações governamentais. Além disso, em algumas regiões do país ocorreram conflitos armados e boicotes que impediram ou dificultaram a participação na votação. Em 2014, eleitores foram às urnas para eleger conselheiros municipais em 56 cidades. Também novos deputados foram eleitos para elaborar a nova constituição do país. Inicialmente, esse grupo constituinte seria formado por 60 membros (o Comitê de Sessenta), mas apenas 47 começaram os trabalhos devido à violência em Derna, centro islâmico no leste, o que inviabilizou as eleições nessa região, além do boicote promovido pelos Amazigh (ou Berberes) em algumas partes do país. No início dos trabalhos, milicianos armados invadiram o Parlamento e suspenderam a legislatura encarregada de redigir a nova constituição nacional. Para agravar ainda mais a instabilidade no país, o 
Artigo original

Hegemonia - Revista Eletrônica de Relações Internacionais do Centro Universitário Unieuro

ISSN: 1809-1261

UNIEURO, Brasília, número 15, 2015, pp. 4-16.

embaixador da Jordânia foi sequestrado em Trípoli por milicianos opositores ao governo.

Em outo momento, homens armados invadiram o Parlamento e abriram fogo contra os deputados, impedindo a eleição do novo chefe de governo. Posteriormente, numa eleição tumultuada, o empresário Ahmed Maiteeq foi eleito premiê e teve o seu nome confirmado pelo presidente do Parlamento. Entretanto, grupos rebeldes que não aceitaram o primeiro-ministro invadiram e controlaram alguns portos petrolíferos, o que representa não apenas a instabilidade política do governo, mas também a crise econômica do Estado com o desmantelamento do setor mais produtivo de sua economia.

Nos permanentes confrontos pelo acesso ao poder e em discordância à eleição de Maiteeq, membros da milícia comandada pelo general Khalifa Haftar entraram em choque com militantes islâmicos da milícia do Ansar al-Sharia. Fato que levou o presidente do Parlamento a pedir para que as milícias islamitas se mobilizassem para impor o controle em Trípoli, depois que as forças secularistas de Haftar invadiram a sede do legislativo. Em seguida, os legisladores, reunidos na cidade de Tobruk, no extremo leste do Líbia, longe dos conflitos entre militantes das milícias rivais, pediram da ONU o empenho na constituição de uma força internacional de intervenção para impedir o crescimento da violência miliciana que dividiu o país.

Haftar, que havia sido general de Khadafi, mas rebelou-se contra este em 1980 e se refugiou nos EUA, declarou-se um nacionalista e opositor do Islamismo Político, a quem acusou de ligação com o grupo terrorista Al-Qaeda. Haftar também acusou a Irmandade Muçulmana de apoiar, através de forças do Catar e da Turquia, grupos terroristas islâmicos, fato que levou os manifestantes de volta às ruas, dessa vez em apoio a Haftar, que também conseguiu agregar o apoio das forças especiais do exército. Diante de tais circunstâncias, a Suprema Corte do país, sob pressão dos protestos nas ruas, dos secularistas, das forças armadas e do poder do general Haftar, anulou a eleição de Ahmed Maiteeq. 
Artigo original

Hegemonia - Revista Eletrônica de Relações Internacionais do Centro Universitário Unieuro

ISSN: $1809-1261$

UNIEURO, Brasília, número 15, 2015, pp. 4-16.

A Líbia, assim como os demais países envolvidos na Primavera Árabe, registrou uma característica comum ao movimento, além do fácil acesso à nova comunicação através das redes sociais, foi a luta crescente por direitos políticos, sociais e civis. Isso favoreceu a formação de uma nova imagem da sociedade e incentivou os movimentos populares. A observação do ocorrido na região, envolvendo populações da vizinhança, incentivou a manifestação popular e de grupos de representação na luta contra o regime autoritário de Khadafi. Após a derrubada do governo, o caminho para a participação política foi aberto e isso, junto às pressões externas, fez com que grupos políticos revisem seus planos de atuação, optando pelo engajamento legal e legítimo no sistema e pela participação pacífica. Porém, com as ações iniciais do governo provisório, grupos que haviam lutado pela queda do governo ditatorial voltaram ao confronto por discordância dessas ações e por não encontrarem espaço no novo governo. Os confrontos se enraizaram em questões ideológicas, latentes no antigo regime, que colocaram em lados opostos Secularistas e Islamitas, defendendo respectivamente o Estado secular (laico) e o Estado religioso (Sharia).

Quanto ao direcionamento do país para a democracia, entendemos que a Líbia caminha progressivamente rumo a este destino, mas em conjunto, o processo ainda nos parece incipiente para ser caracterizado como democrático, apesar de seguir uma política de abertura e garantias de liberdades. É inegável que na mudança de regime um esforço extraordinário foi e está sendo realizado rumo à democracia, começando com as Eleições Legislativas realizadas em 2012, as Eleições Municipais e a Eleição do Comitê de Sessenta, em 2014, sinalizado que a Líbia está no caminho da construção democrática, apesar das dificuldades presentes.

Consideramos que o isolamento decretado pela ONU, a crise econômica interna, a guerra do governo dos EUA contra o terrorismo institucionalizado por Khadafi e as manifestações revolucionárias nos países vizinhos deslocaram a pressão da população e das instituições líbias para a cobrança por uma abertura democrática. As mudanças tiveram grande alcance tanto no âmbito governamental, quanto no 
Artigo original

Hegemonia - Revista Eletrônica de Relações Internacionais do Centro Universitário Unieuro

ISSN: $1809-1261$

UNIEURO, Brasília, número 15, 2015, pp. 4-16.

da sociedade civil, além do campo econômico e dos direitos. Por essas razões, enxergamos um processo ainda em fase embrionária, de certa forma com base incipiente a qualquer constatação de consolidação democrática a curto prazo, de onde concluímos que, dada a instabilidade no Parlamento, com a dificuldade operacional dos congressistas, e a fragilidade do governo, inclusive com as sucessivas alterações do primeiro-ministro, não é possível nesses anos iniciais, subsequentes à derrubada do regime autoritário, proclamar o Estado líbio como democrático, face ao simultâneo estado de transformação e conservação em que se encontra a sociedade e às incertezas no estabelecimento do diálogo em superação aos conflitos entre grupos rivais.

Referências

AL-ALIMI, Ziad. A Irmandade Muçulmana: primeiros beneficiários, primeiros perdedores. Jornal Alarab, Londres, n. 9542, p. 6, 28 abr. 2014.

ALFADL, Munder. O Islamismo Político: o padrão e o modo de pensar. Beirute: Alhiwar Almutamadin, 2003.

ARRGAEI, Saleem Nasr. Khadafi incitou a matar os adversários? Jornal Líbia Almustaqbal, 19 ago. 2009.

IBRAHEEM, Muhammad Yusri. As participações políticas contemporâneas à luz da política de Sharia. Cairo: Dar Alyusr, 2011. ZAHIR, Muhammad Kamil. O conceito entre a corrente secular e a religiosa no pensamento árabe moderno e contemporâneo. Beirute: Dar Albairouni, 1994. 